\title{
Analisis Video Comments to Likes Ratio Tiktok Pada 7 Youtuber PUBG Mobile
}

\author{
I Dewa Gede Adi Suantara \\ STMIK STIKOM Indonesia \\ Adikantin02@gmail.com
}

\begin{abstract}
Tik Tok is a short video platform developed by a Chinese company. The social media application Tik tok allows its users to be creative with music, filters, and several other features with video durations from 15 seconds to 1 minute. The United States occupies the top rank of Tik Tok users with 65.9 million, while Indonesia ranks fourth with 30.7 million users in 2020. The large number of active Tik Tok users in Indonesia can certainly provide opportunities for online game YouTubers. especially PUBG Mobile to make tik tok social media a marketing medium. There are 7 PUBG Mobile Youtubers who use tik tok social media as marketing media, including; Bang Alex, EJ Gaming, Kimi Hime, Benny Moza, Sarah Vilod, Bang Pen, and Zuxxy Gaming. This study aims to calculate the credibility of the tik tok 7 Youtuber PUBG Mobile account performance using quantitative methods. The results of this study show that youtubers from the Zuxxy Gaming account get the first rank and have good account performance credibility.
\end{abstract}

\begin{abstract}
ABSTRAK
Tik tok merupakan flatform video pendek yang dikembangkan oleh perusahaan asal tiongkok. Aplikasi media sosial Tik tok memungkinkan penggunannya untuk berkreasi dengan musik, filter, dan beberapa fitur lainnya dengan durasi video 15 detik sampai 1 menit. Negara amerika serikat menempati peringkat teratas pengguna tik tok dengan jumlah 65,9 juta, sedangkan di negara Indonesia menempati peringkat keempat dengan jumlah 30,7 juta pengguna pada tahun 2020. Banyaknya pengguna tik tok yang aktif di Indonesia tentu dapat memberikan peluang bagi youtuber game online khususnya PUBG Mobile untuk menjadikan media sosial tik tok sebagai media marketing. Adapun 7 Youtuber PUBG Mobile yang memanfaatkan media sosial tik tok sebgai media marketing, diantaranya; Bang Alex, EJ Gaming, Kimi Hime, Benny Moza, Sarah Vilod, Bang Pen, dan Zuxxy Gaming. Penelitian ini bertujuan untuk menghitung kredibilitas dari performa akun tik tok 7 Youtuber PUBG Mobile dengan menggunakan metode kuantitatif. Hasil dari penelitian ini menunjukan bahwa youtuber dari akun Zuxxy Gaming mendapatkan peringkat pertama dan memiliki kredibilitas performa akun yang baik.
\end{abstract}

Keyword : Sosial Media TikTok ; PUBG Mobile, Video Comments to Likes Ratio ; Bang Alex

\section{PENDAHULUAN}

Media sosial telah menjadi kebutuhan baru dalam berinteraksi di era informasi ini. Pada umumnya fungsi dari media sosial diantaranya untuk berbagi pesan dengan banyak pengguna media sosial itu sendiri,yaitu berupa berita (informasi), gambar (foto) dan juga tautan video. Media sosial tidak hanya dapat di akses di perangkat komputer, tetapi dengan adanya aplikasi di smartphone atau telepon pintar, 
maka semakin memudahkan masyarakat untuk mengakses media sosial secara mobile sehingga dapat diakses kapanpun dan di manapun. (Prianbodo, 2018)

Beberapa aplikasi hadir untuk membantu pengguna dalam melakukan kegiatan sehari-harinya seperti, aplikasi olahraga, aplikasi memasak, money manager, bahkan aplikasi untuk interaksi sosial. Aplikasi interaksi sosial yang hadir akan sulit jika dihitung dengan jari karena cukup banyak. Salah satunya terdapat pada aplikasi Tik Tok yang berasal dari perusahaan teknologi asal Singapura, Bytemod, menghadirkan aplikasi edit video bernama "Tik Tok". (Susilowati, 2018). Pada Journal (Ruth \& Candraningrum, 2020) menjelaskan menurut Sensor Tower, sebuah lembaga penyedia survei mengenai aplikasi ekonomi global asal Amerika Serikat, Tiktok berhasil menjadi aplikasi nomor 1 yang paling banyak diunduh pada tahun 2019 sebanyak 1 milliar kali di App Store dan Google Play dan berhasil meraih kepopuleran tertinggi di 6 negara dan salah satunya adalah Indonesia.

Pada aplikasi Tik Tok ini pengguna dapat membuat video yang hanya berdurasi kurang lebih 30 detik dengan memberikan special effects yang unik dan menarik serta memiliki dukungan musik yang banyak sehingga penggunanya dapat melakukan performa dengan beragam gaya ataupun tarian. Semakin melejitnya aplikasi Tik Tok ini menjadi aplikasi favorit baru bagi para pengguna media sosial khususnya youtube, dengan tujuan agar video-video pendek tersebut setelah diunggah dapat dilihat oleh pengikutnya (subcribe), dan tidak sedikit yang akhirnya banyak yang mengagumi atau menyukai kiriman video-video tersebut sehingga menjadi booming, dengan maraknya jumlah pengguna tiktok tentu dapat membuka pelung bagi youtuber untuk menjadikan platform ini sebagai platform digital maketing. Ada banyak akun youtuber terkenal yang ada pada platform Tiktok, sebagai contoh yaitu Youtuber Gamers. Adapun Top 7 Youtuber PUBG Mobile, diantaranya yaitu ; Bang Alex, EJ Gaming, Kimi Hime, Benny Moza, Sarah Viloid, Bang Pen, dan Zuxxy Gaming ("7 YouTuber PUBG Mobile Yang Wajib Ditonton - Kotak.Game.Com,” n.d.).

Penelitian ini menggunakan metode eksploratif kuantitatif, dan akan menghitung menggunakan rasio rasio yang ada pada tiktok. Pada penelitian (Permana \& Meinarni, 2021) menjelaskan bahwa terdapat 17 rasio yang ada pada sosial media Tiktok dan relevan digunakan sebagai media ukur kredibilitas akun yang ada.Penelitian ini hanya berfokus untuk menghitung kredibilitas Video Comments to Likes Ratio pada 7 Youtuber PUBG Mobile. Tujuan dari penelitian ini adalah mengetahui kredibilitas performa dari akun Tiktok 7 Youtuber PUBG Mobile menggunakan Video Comments to Likes Ratio.

\section{TINJAUAN PUSTAKA}

Media Sosial semakin menjadi komponen utama dalam hidup kita, platform media sosial berkontribusi pada aliran informasi, video, dan forum gambar yang ada. Bagian dari komunitas yang lebih besar. Media sosial tidak bisa lagi diabaikan dalam agenda keseharian kehidupan pribadi masyarakat dan opini politik. Sebagian besar platform media sosial telah menghasilkan aliran peluang pendapatan baru, karena jejaring sosial penampilan influencer telah menjadi identik dengan kemungkinan ketenaran non-talenta karena semakin banyak yang menggunakan platform untuk menciptakan karier bagi diri mereka sendiri. Ada banyak sekali aplikasi yang dapat membantu kehidupan masyarakat dalam berkomunikasi, seperti Instagram, tiktok, twitter, facebook dan masih banyak lagi.

Tiktok merupakan salah satu jenis media sosial dan saat ini tidak kalah dengan media sosial lain seperti Twitter dan Instagram. Media sosial ini kembali populer setelah populer pada tahun 2015 karena dianggap "alay".(Tina Katika, 2021). 
Tiktok yang merupakan platform social video pendek yang didukung dengan musik. Baik itu musik tarian, gaya bebas (freestyle) dan performa, para pembuat video yang didorong untuk sekreatif mungkin berimajinasi sebebas-bebasnya dan menyatakan ekspresi mereka dengan semenarik mungkin. Aplikasi tersebut menyuguhkan special effect diantaranya effect shaking dan shivering biasa digunakan pada video dengan electronic music, tidak hanya efek tersebut yang menjadi unggulan "TikTok" daripada aplikasi video musik lainnya. Aplikasi tersebut juga bisa merubah warna rambut, sticker 3D dan lain lain.

Aplikasi tiktok dibuat untuk menghibur pengguna lainnya. Peneliti (Prianbodo, 2018) menyatakan cara untuk mendapatkan aplikasi tersebut sangatlah mudah, mereka bisa mengunduh aplikasi tersebut melalui aplikasi smarthphone playstore atau dari google.

Tiktok banyak memberika informasi berguna seperti tutorial belajar, tutorial masak, hiburan musik, menari, mecari pasangan, membantu orang, jualan, tempat bercerita bahkan informasi informasi tentang pendidikan sudah ada di Tiktok.(Tina Katika, 2021).

Aplikasi TikTok juga dapat dijadikan peluang bagi content creator sebagai platform social media marketing, sehingga TikTok mampu memberikan peluang yang sangat tinggi bagi content creator khususnya indonesia dalam melakukan digital marketing. TikTok dirasakan memiliki kekuatan ataupun pengaruh dalam industri, sehingga menimbulkan kualitas akun yang menentukan strata maupun kredibilitas pemilik akun. Kredibilitas akun TikTok merupakan suatu hal yang cukup penting untuk berbagai kepentingan. Kredibilitas sebuah akun TikTok dapat diukur dari tingkat performa yang dihasilkan secara matematis. Dalam mengukur performa diperlukan skala pengukuran yang tertuang ke dalam rasio.

\section{METODE PENELITIAN}

Dalam kasus penelitian ini, peneliti menggunakan metode eksploratif kuantitatif untuk mengetahui kredibilitas dari akun Tiktok Pada 7 Youtuber PUBG Mobile.

Dari penelitian ini bertujuan unutk mengetahui nilai kredibilitas dari performa akun Tiktok 7 Youtuber PUBG Mobile. Dalam perhitungan ini, terdapat beberapa langkah yang harus dilakukan dalam penelitian ini, sehingga mampu menemukan peringkat pertama akun Tiktok Youtuber PUBG Mobile yang memiliki performa terbaik. Langkah langkah yang dilakukan pada penelitian ini, yaitu:

\section{Melakukan Eksplorasi Pada Website Untuk Menentukan Objek Yang Akan Dianalisa.}

Eksplorasi ini dilakukan pada beberapa halaman website yang menyediakan informasi mengenai objek yang akan di teliti. Setelah eksplorasi tersebut selesai dilakukan, akan ditemukan nama nama youtuber PUBG Mobile yang akan dijadikan objek analisa. Langkah selanjutnya adalah mencari nama akun Tiktok dari masing-masing youtuber PUBG Mobile dan pastikan semua Youtuber Mempunyai akun pada aplikasi sosial media tiktok.

\section{Menghitung Nilai Rata-Rata Variable Dari 7 Youtuber PUBG Mobile.}

Dalam langkah ini, peneliti melalukan perhitungan nilai variable video comment dan likes. Variable merupakan segala sesuatu yang akan menjadi objek dalam sebuah penelitian (Astriani, 2014). Untuk menghitung nilai rata rata dari variable video comment dan variable likes yaitu dengan cara mengambil minimal 10 postingan kemudian di hitung sehingga menemukan nilai rata-rata dari masing masing variable. 


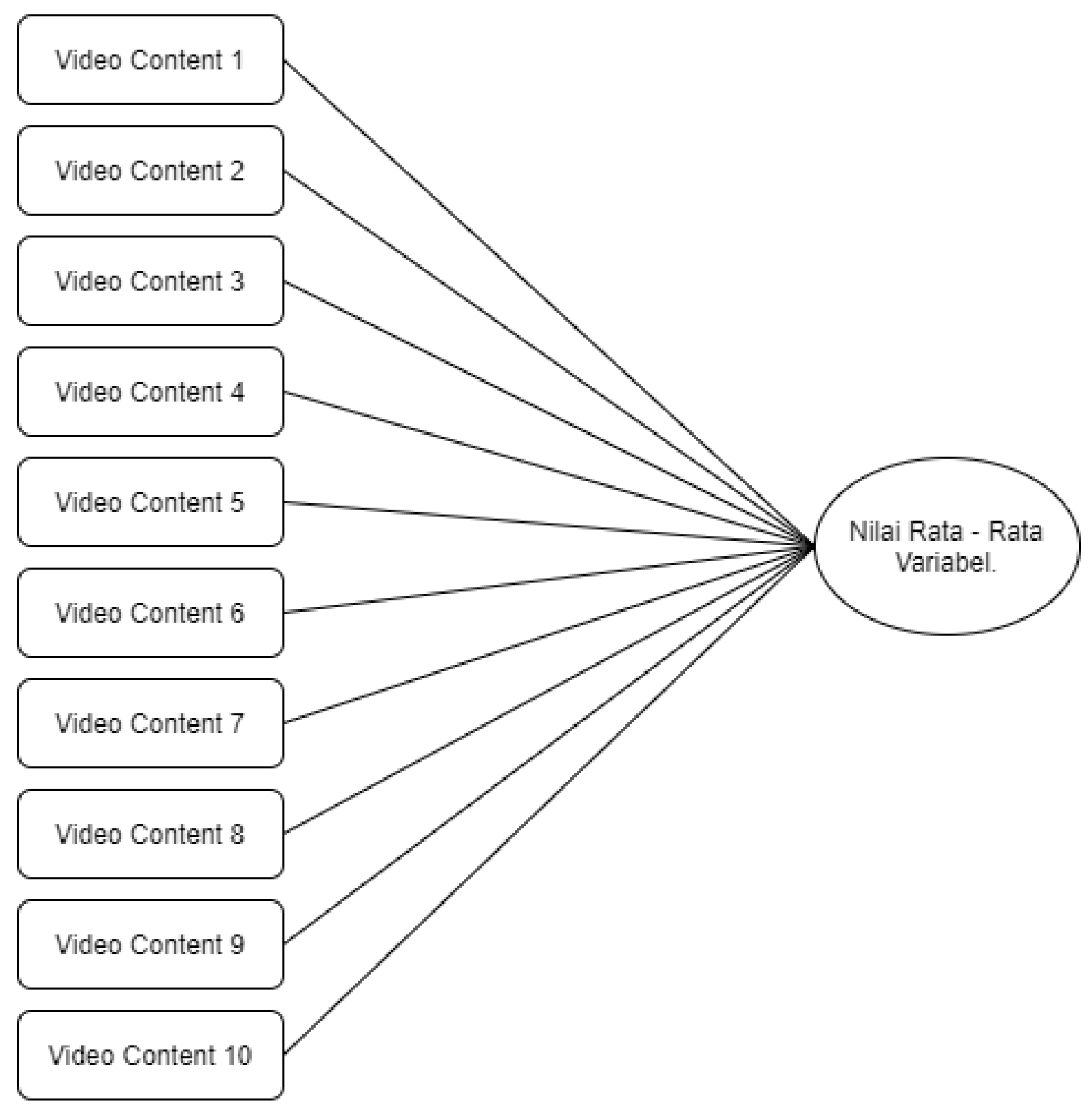

3. Menghitung Nilai Kredibilitas Rasio.

Dalam menghitung nilai kredibilitas dari video Comment to Likes ratio, peneliti menggunakan cara membagi nilai variable pertama dengan variable kedua. Jika video comment mempunyai nilai 200 dan video like memiliki nilai 300, maka cara menghitungnya yaitu $200: 300=0,6$. Dengan demikian dapat diperoleh hasil nilai dari video Comment to Likes ratio adalah 0,6

\section{Menentukan Peringkat Pada Akun Tiktok.}

Langkah yang terakhir dalam penelitian ini yaitu menentukan peringkat dari masing masing rasio yang ada. Saat menentukan peringkat perlu melihat karakteristik dari rasio yang di teliti. Jika karakteristik rasio bernilai tinggi, maka objek yang akan memiliki nilai tinggi akan mendapat angka 7 dan objek yang memperoleh nilai tinggi akan mendapatkan angka 1. Setelah mendapatkan hasil kredibilitas ratio maka dapat disimpulkan objek yang mana yang memperoleh peringkat 1 sampai dengan peringkat 7 . 


\title{
4. HASIL DAN PEMBAHASAN
}

Akun TikTok dari 7 Youtuber PUBG Mobile, diantaranya :

1. Bang Alex

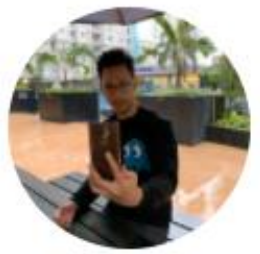

\section{bangalex 0}

BangAlex

Follow

\author{
20 Following $184.5 \mathrm{~K}$ Followers $3.2 \mathrm{M}$ Likes \\ Instagram: @bangalexO \\ FB Gaming: BANG ALEX \\ $\odot$ www.youtube.com/c/BANGAL...
}

Gambar 1. Akun TikTok Bang Alex

Sumber : https://www.tiktok.com/@bangalex0 (akses pada 20-10-2021)

2. EJ Gaming

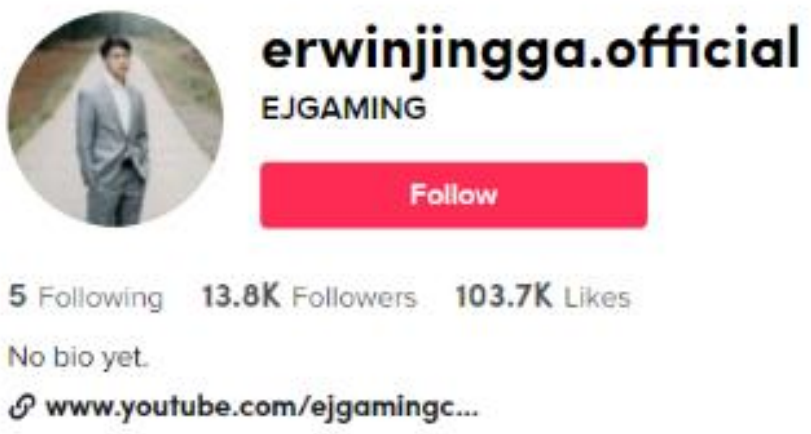

Gambar 2. Akun TikTok EJ Gaming

Sumber : https://www.tiktok.com/@erwinjingga.official (akses pada 20-10-2021) 
3. Kimi Hime

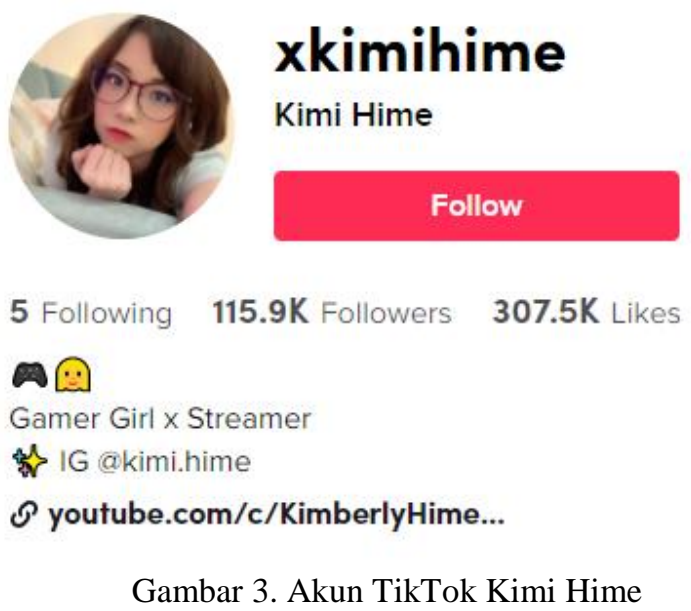

Sumber : https://www.tiktok.com/@xkimihime (akses pada 20-10-2021)

4. Benny Moza

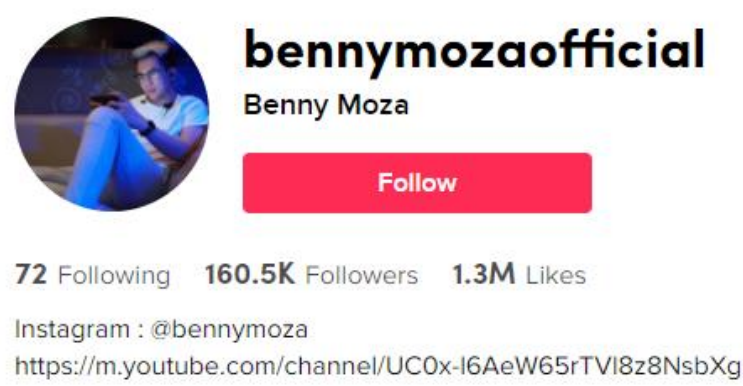

Gambar 4. Akun TikTok Benny Moza

Sumber : https://www.tiktok.com/@bennymozaofficial (akses pada 20-10-2021)

5. Sarah Viloid

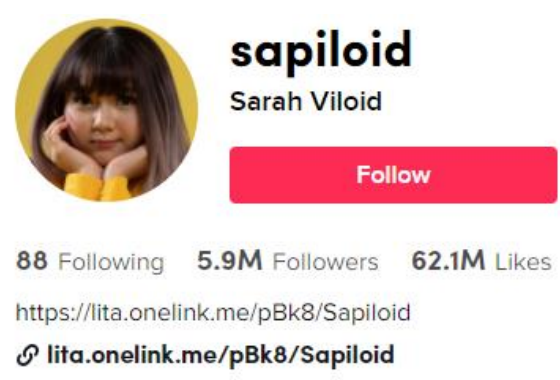

Gambar 5. Akun TikTok Sarah Viloid

Sumber : https://www.tiktok.com/@sapiloid (akses pada 20-10-2021) 
6. Bang Pen

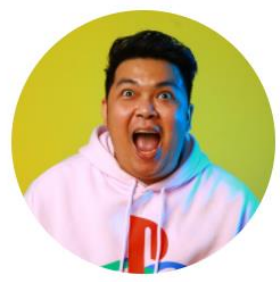

\section{bangpennnnn}

\section{Bangpen}

\section{Follow}

\section{Following 197.1K Followers 2.6M Likes}

normaL is too boring

Gambar 6. Akun TikTok Bang Pen

Sumber : https://www.tiktok.com/@bangpennnnn (akses pada 20-10-2021)

7. Zuxxy Gaming

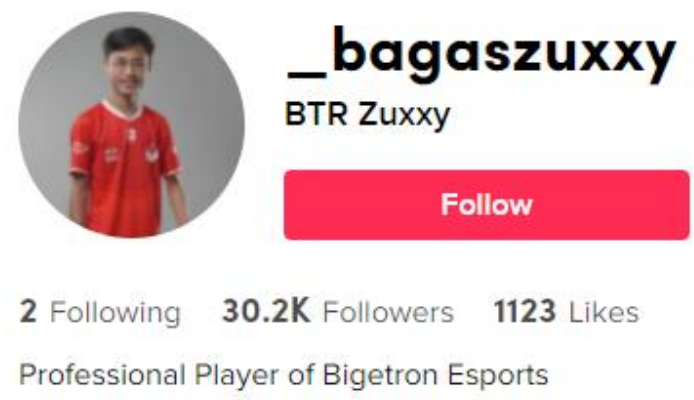

Gambar 7. Akun TikTok Zuxxy Gaming

Sumber : https://www.tiktok.com/@ bagaszuxxy (akses pada 20-10-2021)

Dari ketujuh akun TikTok 7Youtuber PUBG Mobile, peneliti menemukan nilai dari masing-masing variabel yang ada untuk menghitung rasio Video Comments to Likes dari setiap akun. Pada akun TikTok terdapat 7 variabel, diantaranya yaitu :

1. Likes

2. Followers

3. Following

4. Video Likes

5. Video Comments

6. Video Share

7. Video Views

Dari ketujuh variabel tersebut peneliti hanya fokus untuk menemukan hasil dari 2 variabel, yaitu :

1. Video Comments

2. Likes

Dari kedua variabel tersebut kemudian dianalisa sehingga menemukan nilai rata-rata dari variabel video comments dan variabel likes. Untuk menghitung nilai rata-rata dari variabel video comments dan 
variabel likes yaitu dengan cara mengambil minimal 10 postingan kemudian di hitung sehingga menemukan nilai rata-rata dari masing-masing variabel. Berikut merupakan tabel nilai rata-rata dari masing-masing youtuber Pubg mobile, yaitu :

Tabel 1. Analisa Nilai Rata-Rata Nilai Variabel Video Comments dan Likes Akun TikTok Bang Alex

\begin{tabular}{|c|c|}
\hline No & Video Comments \\
\hline 1 & 34 \\
\hline 2 & 16 \\
\hline 3 & 632 \\
\hline 4 & 137 \\
\hline 5 & 194 \\
\hline 6 & 217 \\
\hline 7 & 114 \\
\hline 8 & 317 \\
\hline 9 & 193 \\
\hline 10 & 63 \\
\hline total & \\
\hline & \\
\end{tabular}

Total Likes

\begin{tabular}{|c|c|}
\hline Nama & Likes \\
\hline Bang Alex & $3,100,000.00$ \\
\hline
\end{tabular}

Sumber : Pengolah Data Excel

Tabel 2. Analisa Nilai Rata-Rata Nilai Variabel Video Comments dan Likes Akun TikTok EJ Gaming

\begin{tabular}{|c|r|}
\hline No & Video Comments \\
\hline 1 & 1 \\
\hline 2 & 4 \\
\hline total & 2.5 \\
\hline
\end{tabular}

\begin{tabular}{|c|}
\hline Likes \\
\hline $103,700.00$ \\
\hline
\end{tabular}

Sumber : Pengolah Data Excel

Tabel 3. Analisa Nilai Rata-Rata Nilai Variabel Video Comments dan Likes Akun TikTok Kimi Hime

\begin{tabular}{|c|r|}
\hline No & Video Comments \\
\hline 1 & 149 \\
\hline 2 & 333 \\
\hline 3 & 2,096 \\
\hline 4 & 177 \\
\hline 5 & 332 \\
\hline 6 & 1,265 \\
\hline 7 & 339 \\
\hline 8 & 270 \\
\hline total & 620.1 \\
\hline
\end{tabular}

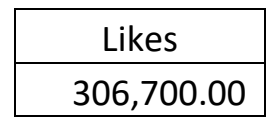

Sumber : Pengolah Data Excel 
Tabel 4. Analisa Nilai Rata-Rata Nilai Variabel Video Comments dan Likes Akun TikTok Benny Moza

\begin{tabular}{|c|c|}
\hline No & Video Comments \\
\hline 1 & 2 \\
\hline 2 & 12 \\
\hline 3 & 14 \\
\hline 4 & 21 \\
\hline 5 & 10 \\
\hline 6 & 47 \\
\hline 7 & 95 \\
\hline 8 & 2 \\
\hline 9 & 14 \\
\hline 10 & 9 \\
\hline total & 22.6 \\
\hline
\end{tabular}

\begin{tabular}{|c|}
\hline Likes \\
\hline $1,300,000.00$ \\
\hline
\end{tabular}

Sumber : Pengolah Data Excel

Tabel 5. Analisa Nilai Rata-Rata Nilai Variabel Video Comments dan Likes Akun TikTok Sarah Viloid

\begin{tabular}{|c|r|}
\hline No & Video Comments \\
\hline 1 & 50 \\
\hline 2 & 230 \\
\hline 3 & 151 \\
\hline 4 & 1,048 \\
\hline 5 & 86 \\
\hline 6 & 101 \\
\hline 7 & 361 \\
\hline 8 & 1,393 \\
\hline 9 & 310 \\
\hline 10 & 4,520 \\
\hline total & 825.0 \\
\hline
\end{tabular}

\begin{tabular}{|c|}
\hline Likes \\
\hline $60,800,000.00$ \\
\hline
\end{tabular}

Sumber : Pengolah Data Excel

Tabel 6. Analisa Nilai Rata-Rata Nilai Variabel Video Comments dan Likes Akun TikTok Bang Pen

\begin{tabular}{|c|r|}
\hline No & Video Comments \\
\hline 1 & 166 \\
\hline 2 & 18 \\
\hline 3 & 35 \\
\hline 4 & 271 \\
\hline 5 & 38 \\
\hline 6 & 71 \\
\hline 7 & 15 \\
\hline 8 & 50 \\
\hline
\end{tabular}




\begin{tabular}{|c|r|}
9 & 16 \\
\hline 10 & 10 \\
\hline total & 69.0 \\
\hline
\end{tabular}

\begin{tabular}{|c|}
\hline Likes \\
\hline $2,600,000.00$ \\
\hline
\end{tabular}

Sumber : Pengolah Data Excel

Tabel 7. Analisa Nilai Rata-Rata Nilai Variabel Video Comments dan Likes Akun TikTok Zuxxy Gaming

\begin{tabular}{|c|r|}
\hline No & Video Comments \\
\hline 1 & 135 \\
\hline total & 135.0 \\
\hline
\end{tabular}

\begin{tabular}{|c|}
\hline Likes \\
\hline $1,029.00$ \\
\hline
\end{tabular}

Sumber : Pengolah Data Excel

Setelah menghitung nilai rata-rata tersebut, maka akan menemukan hasil akhir nilai rata-rata dari variabel video comments dan variabel likes ratio

Tabel 8. Nilai Variabel Pada Akun TikTok 7Youtuber PUBG Mobile

\begin{tabular}{|l|r|r|l|r|r|r|r|}
\hline Variable & Bang Alex & EJ Gaming & $\begin{array}{l}\text { Kimi } \\
\text { Hime }\end{array}$ & Beny Moza & Sarah Viloid & Bang Pen & $\begin{array}{l}\text { Zuxxy } \\
\text { Gaming }\end{array}$ \\
\hline Video comments & 191.7 & 2.5 & 620.1 & 22.6 & 825.0 & 69.0 & 135.0 \\
\hline Likes & $103,700.00$ & $103,700.00$ & $306,700.00$ & $1,300,000.00$ & $60,800,000.00$ & $2,600,000.00$ & $1,029.00$ \\
\hline
\end{tabular}

Sumber : Pengolah Data Excel

Pada akun TikTok terdapat 17 rasio yang relevan digunakan untuk mengukur kredibilitas pada masingmasing akun. Namun pada penelitian kali ini hanya berfokus untuk menghitung Video Comments to Likes Ratio. Untuk menghitung kredibilitas dari masing-masing akun TikTok setiap Youtuber, peneliti menghitung dengan cara : variabel 1 akan dibagi dengan variabel 2, sehingga ditemukan hasil analisisa dari rasio tersebut.

Tabel 9. Hasil Perhitungan Rasio Akun TikTok

\begin{tabular}{|l|c|c|c|c|c|c|c|}
\hline \multicolumn{1}{|c|}{ RATIO } & Bang Alex & EJ Gaming & Kimi Hime & $\begin{array}{c}\text { Beny } \\
\text { Moza }\end{array}$ & $\begin{array}{c}\text { Sarah } \\
\text { Viloid }\end{array}$ & Bang Pen & $\begin{array}{c}\text { Zuxxy } \\
\text { Gaming }\end{array}$ \\
\hline $\begin{array}{l}\text { Video } \\
\begin{array}{l}\text { Comments } \\
\text { to Likes } \\
\text { Ratio }\end{array}\end{array}$ & $\begin{array}{c}0.0000618 \\
3871\end{array}$ & $\begin{array}{c}0.0000241 \\
0800\end{array}$ & $\begin{array}{c}0.0020219 \\
2696\end{array}$ & $\begin{array}{c}0.0000173 \\
8462\end{array}$ & $\begin{array}{c}0.0000135 \\
6908\end{array}$ & $\begin{array}{c}0.0000265 \\
3846\end{array}$ & $\begin{array}{c}0.13119533 \\
5528\end{array}$ \\
\hline
\end{tabular}


Video Comments to Likes Ratio memiliki karakteristik yang tinggi, artinya semakin tinggi nilai yang dihasilkan maka semakin baik kredibilitas dari performa akun tersebut. Untuk memberikan peringkat pada masing-masing Youtuber, peneliti memberikan angka 7 kepada vendor yang mendapatkan nilai tertinggi dan angka 1 untuk vendor smartphone yang mendapatkan nilai terendah. Berikut merupakan tabel urutan nilai yang dihasilkan oleh masing-masing Youtuber.

Tabel 10. Nilai Rasio Akun TikTok 7 Youtuber PUBG Mobile

\begin{tabular}{|l|c|c|c|c|c|c|c|}
\hline \multirow{2}{*}{ RATIO } & \multicolumn{7}{|c|}{ Nilai } \\
\cline { 2 - 8 } & $\begin{array}{c}\text { Bang } \\
\text { Alex }\end{array}$ & $\begin{array}{c}\text { EJ } \\
\text { Gaming }\end{array}$ & $\begin{array}{c}\text { Kimi } \\
\text { Hime }\end{array}$ & $\begin{array}{c}\text { Beny } \\
\text { Moza }\end{array}$ & $\begin{array}{c}\text { Sarah } \\
\text { Viloid }\end{array}$ & $\begin{array}{c}\text { Bang } \\
\text { Pen }\end{array}$ & $\begin{array}{c}\text { Zuxxy } \\
\text { Gaming }\end{array}$ \\
\hline $\begin{array}{l}\text { Video } \\
\begin{array}{l}\text { Comments to } \\
\text { Likes Ratio }\end{array}\end{array}$ & 5 & 3 & 6 & 2 & 1 & 4 & 7 \\
\hline
\end{tabular}

Dari Tabel Nilai Rasio Akun TikTok 7 Youtuber PUBG Mobile dapat simpulkan bahwa Zuxxy Gaming mendapatkan nilai tertinggi untuk rasio Video Comments to Like. Sedangkan akun TikTok Sarah Viloid mendapatkan nilai terendah untuk rasio ini. Jadi, pada penelitian ini Zuxxy Gaming memiliki kredibilitas performa yang lebih baik dibandingkan dengan Youtuber Pubg yang lainnya.

\section{KESIMPULAN}

Tujuan dari penelitian ini adalah mengetahui kredibilitas performa dari akun TikTok 7 Youtuber PUBG Mobile menggunakan Video Comments to Likes Ratio. 7 Youtuber PUBG Mobile tersebut diantaranya : Bang Alex, EJ Gaming, Kimi Hime, Benny Moza, Sarah Viloid, Bang Pen, Zuxxy Gaming. Dari Ketujuh Youtuber tersebut dapat disimpulkan bahwa :

1. Peringkat pertama diraih oleh Youtuber Zuxxy Gaming dengan nilai tertinggi yaitu 0.13119533528

2. Peringkat kedua diraih oleh Youtuber Kimi Hime dengan nilai yaitu 0.00202192696

3. Peringkat ketiga diraih oleh Youtuber Bang Alex dengan nilai yaitu 0.00006183871

4. Peringkat keempat diraih oleh Youtuber Bang Pen dengan nilai yaitu 0.00002653846

5. Peringkat kelima diraih oleh Youtuber EJ Gaming dengan nilai yaitu 0.00002410800

6. Peringkat keempat diraih oleh Youtuber Beny Moza dengan nilai yaitu 0.00001738462

7. Peringkat ketujuh diraih oleh Youtuber Sarah Viloid dengan nilai terendah yaitu 0.00001356908 


\section{DAFTAR PUSTAKA}

"7 YouTuber PUBG Mobile yang Wajib Ditonton - kotak.game.com." (n.d.). https://www.kotakgame.com/minifeature/detail/0/3975/7-YouTuber-PUBG-Mobileyang-Wajib-Ditonton

Astriani, I. N. (2014). Analisis Pengaruh Kualitas Layanan Terhadap Kepuasan Konsumen (Studi Kasus Pelanggan Produk Busana Muslim Pada Tik-Tok Boutique Karawang Barat). STIE Indonesia Banking School.

Fanaqi, C. (2021). Tiktok Sebagai Media Kreativitas di Masa Pandemi Covid-19. Jurnal Dakwah, 22(1), 105-130.

Permana, I. P. H., \& Meinarni, N. P. S. (2021). Ratio Analysis on Tiktok (Social Media) for Qualitative Research Using Explorative Methods. Jurnal Ekonomi \& Bisnis JAGADITHA, 8(1), 30-38.

Prianbodo, B. (2018). Pengaruh “Tiktok” Terhadap Kreativitas Remaja Surabaya. StikosaAWS.

Puspitarini, D. S., \& Nuraeni, R. (2019). Pemanfaatan Media Sosial Sebagai Media Promosi. Jurnal Common, 3(1), 71-80.

Ruth, D., \& Candraningrum, D. A. (2020). Pengaruh Motif Penggunaan Media Baru Tiktok terhadap Personal Branding Generasi Milenial di Instagram. Koneksi, 4(2), 207-214.

Soliha, S. F. (2015). Tingkat ketergantungan pengguna media sosial dan kecemasan sosial. Interaksi: Jurnal Ilmu Komunikasi, 4(1), 1-10.

Susilowati, S. (2018). Pemanfaatan Aplikasi Tiktok Sebagai Personal Branding Di Instagram (Studi Deskriptif Kualitatif Pada Akun@bowo_allpennliebe). Jurnal Komunikasi, 9(2), 176-185.

Tina Katika, T. (2021). Analisis Fenomenologi Hashtag\# tiktokdoyourmagic Terhadap Kesadaran Berbagi di Masyarakat. JURNAL SAINS SOSIAL DAN HUMANIORA, 5(2), $115-122$. 